\title{
O desenvolvimento dos princípios de justiça na criança ${ }^{1}$
}

\section{The development of justice principles in the child}

\author{
Dirce Shizuko Fujisawa
}

\begin{abstract}
Resumo
Embora realizados há setenta anos , os estudos de Piaget referentes ao desenvolvimento sócio-moral da criança são valiosos e significativos. Este trabalho tem por objetivo investigar o desenvolvimento moral de um grupo de crianças, com base nos estudos realizado por Piaget. Foi realizada uma entrevista semiestruturada coletiva como procedimento de coleta de informações, posteriormente, os dados foram analisados qualitativamente. Foram contadas cinco histórias padronizadas, extraídas dos estudos de Piaget (1994). De acordo com o desenvolvimento sócio-moral descrito por Piaget, os resultados obtidos na entrevista, por meio de histórias padronizadas, evidenciaram que os participantes estão não fase de autonomia ou de cooperação, com tendência predominante a igualdade em seus julgamentos.
\end{abstract}

Palavras-chave: Desenvolvimento, desenvolvimento moral, justiça.

\begin{abstract}
Piaget's studies concerning the social-moral development of the child are valuable and significant. However, they were carried out seventy years ago. The aim of this study is, therefore, to investigate the moral development of a group of children, based on Piaget's previous studies. The data were collected by carrying out a semi-structured interview in order to obtain relevant information. Afterwards, the data were qualitatively analyzed. As an initial procedure, five standard histories from Piaget's studies were told to the participants. According to the social moral development theory, the findings showed that the participants are in the autonomy or cooperation phase, with strong tendency to equality in their judgements.
\end{abstract}

Key words: Child's social-moral development, Justice, Piaget's studies.

\section{Introdução}

Os estudos de Piaget (1994) referentes ao desenvolvimento sócio-moral da criança são valiosos e significativos, e podem contribuir no direcionamento e re-direcionamento da educação infantil, seja pela família, seja pelos professores. Tais estudos foram realizados por Piaget há setenta anos atrás, o que torna necessário verificar se o desenvolvimento sócio-moral ainda ocorre de acordo com o modelo proposto pelo autor. Este trabalho tem por objetivo investigar o desenvolvimento moral de um grupo de crianças, com base nos estudos realizado por Piaget. Este trabalho é um estudo piloto, envolven-

\footnotetext{
1 Trabalho de conclusão da disciplina "Desenvolvimento sócio-moral na perspectiva Piagetiana", ministrada pelo Prof. Dr. Raul Aragão Martins, no programa de Pós-graduação em Educação, na Universidade Estadual Paulista - UNESP - Campus de Marília.

2 Fisioterapeuta, mestre e doutoranda em Educação, área de concentração "Ensino na Educação Brasileira", na Universidade Estadual Paulista - UNESP - Campus de Marília. Docente do Departamento de Fisioterapia da Universidade Estadual de Londrina. Membro do Grupo de Pesquisa “Deficiências Físicas e Sensoriais”. Endereço para contato: Rua Jorge Velho, 784/ apto 202 - centro - Londrina - PR - CEP 86010-510. Fone: 43-3220494. E-mail: dirce07@ sercomtel.com.br
} 
do uma pesquisa com um número reduzido de participantes. Além disso, deve-se considerar a complexidade teórica e as variáveis que interferem no desenvolvimento e julgamento sócio-moral da criança brasileira, pois essas variáveis são diferentes daquelas próprias aos estudos de Piaget.

\section{O Desenvolvimento da Noção de Justiça na Criança}

As regras de justiça, por assim dizer, promovem o equilíbrio das relações sociais. Para Biaggio (1972), "a essência da moralidade está no respeito que o indivíduo adquire pelas regras" (p. 17). Nesse sentido, é fundamental reconhecer como a criança adquire respeito pelas regras existentes na sociedade.

\section{A teoria do desenvolvimento moral de Piaget}

Piaget (1994) propõe a existência de um pré-estágio e de dois estágios de desenvolvimento moral, relativos à consciência de regra, que são:

Pré-estágio - o egocêntrico: a criança é considerada amoral, não há ainda a consciência de regra, pois está centrada em si mesma. No jogo social infantil da criança de 2 a 3 anos, a regra é apenas motora, podendo ser confundida com o hábito. A regra motora, segundo Sales (2000), é decorrente de uma espécie de sentimento da repetição dos esquemas de adaptação motora, ou seja, um hábito.

Primeiro estágio - o realismo moral: a criança considera que os deveres e os valores são subsistentes em si mesmos (exterior e de origem transcendental), independentes da consciência, e impostos obrigatoriamente em quaisquer circunstâncias. Martins (1986) salienta três características principais do realismo moral: na primeira, o dever é heterônimo, sendo considerado o bem como a obediência rigorosa à regra e ao adulto, pois, para a criança, a regra é proveniente do adulto; na segunda, é a palavra e não o espírito da lei que deve ser observada; e na terceira, a concepção objetiva de respon- sabilidade, isto é, o ator é julgado pelas consequências e não pela intenção do ato.

Segundo estágio - é o da autonomia ou cooperação: faz-se fundamental, neste estágio, o sentimento de respeito mútuo e o julgamento tem como base a solidariedade entre os pares. A heteronomia passa a ser recíproca e $\mathrm{o}$ ato que, anteriormente, era julgado pelas consequências passa a ser julgado pelas intenções do ator. Tal fato, o julgamento em função das intenções (responsabilidade subjetiva), é a conduta predominante em crianças com 9 anos em média. Sales (2000) acrescenta que, nesse momento, a regra passa a ser fator e produto da personalidade e a sua verdade não está na tradição, mas no acordo mútuo e na reciprocidade.

\section{Justiça retributiva e distributiva}

Piaget (1994) diferencia a justiça em dois tipos: a retributiva, que se define pela proporcionalidade entre o ato e a sanção; e a distributiva, que implica apenas a noção de igualdade. A justiça retributiva é a mais primitiva das duas noções de justiça. Pode-se dizer que uma sanção é injusta quando pune um inocente, recompensa um culpado ou não é dosada na proporção do mérito ou da falta. Já na justiça distributiva é injusto uma repartição que favorece uns à custa de outros.

A sanção tem como propósito a recolocação da ordem, o reestabelecimento do elo social e da autoridade da regra, e pode ser de dois tipos: expiatória ou de reciprocidade.

A sanção expiatória é paralela a coação, ou seja, uma regra imposta de fora à consciência do indivíduo a qual transgride. É de caráter arbitrário, não há relação entre o conteúdo da sanção e a natureza do ato sancionado, mas é necessário a proporcionalidade entre o sofrimento imposto e a gravidade da falta.

A sanção por reciprocidade é paralela à cooperação e as regras de igualdade surgem do interior da criança. Ou seja, a ruptura do elo social provocado pelo culpado faz sentir seus efeitos. É motivada, há relação de conteúdo e de natureza entre a falta e a punição. 
Segundo Piaget (1994), os resultados das pesquisas acerca da sanção demonstraram que: nas crianças pequenas, a sanção é necessária e justa, tanto mais justa quanto mais severa e a criança devidamente castigada saberá melhor cumprir seu dever; nas crianças maiores, a sanção não constitui uma necessidade moral e a repreensão e a explicação são mais proveitosas que o castigo. Vale salientar que a necessidade de sanção pode ser encontrada em qualquer idade, dependendo do tipo de relações familiares ou sociais. Quanto à reincidência de um ato inadequado e sua sanção, as crianças pequenas consideram que frente à punição não reincidiriam na falta, porque compreendem a autoridade exterior e coercitiva da regra. Já para as crianças maiores, na grande maioria, a compreensão mediante a explicação e sem punição levaria a uma menor reincidência.

Martins (1986) argumenta que, quando a criança entra na sociedade, depara-se com um sistema de regras elaboradas e dominadas pelo adulto. Essas regras são consideradas pelas crianças, até mais ou menos 7 a 8 anos de idade, como sagradas, e quando não são respeitadas, a irritação do adulto é tida como justa, devido ao respeito unilateral, e assim, "castigos" podem ser aplicados. Uma vez que, os efeitos do respeito unilateral tendem a se atenuar com a idade, por volta dos 8 aos 11 anos de idade, a expiação perde progressivamente seu valor e as sanções tendem a ser por reciprocidade (respeito mútuo). A passagem do desenvolvimento moral, da obediência para a cooperação tem como um dos motivadores as experiências morais da criança. A descoberta da imperfeição da justiça adulta é inevitável, e torna-se uma forte contribuição para que ela acredite menos em uma justiça universal e automática. Assim, é necessário fazer o "culpado" compreender a sua falta, por medidas apropriadas, demonstrando a ruptura do elo de solidariedade. Nessa fase, a criança acredita que a punição é inútil, o essencial é a compreensão de sua má ação, que controla as regras da cooperação.

Em definitivo, ocorre a primazia da justiça distributiva (da noção de igualdade) sobre a justiça retributiva. É possível dizer que: as idéias igualitárias se impõem, em função da cooperação, e constituem, assim, uma forma de justiça que, sem estar em contradição com as formas evoluídas da justiça retributiva (a sanção por reciprocidade é devida, justamente, aos progressos destas noções), se opõe às formas primitivas de sanção e termina, mesmo, por fazer que a igualdade tenha primazia sobre a retribuição, sempre que haja conflito entre elas (Piaget, 1994, p. 200).

Na fase de predominância das tendências igualitárias, a criança tende a compreender a situação internamente, sob a influência, das experiências vivenciadas ou observadas, e não simula mais lições de moral como anteriormente, quando defendia a sanção. Novamente, é bem frequente que a injustiça sofrida faça a criança tomar consciência das leis de igualdade. Por outro lado, a igualdade cresce com a solidariedade.

Por volta dos 11 a 12 anos de idade, o igualitarismo simples cede lugar a uma noção de justiça mais refinada, "a equidade", que se define pela igualdade, considerando a situação particular de cada um. Assim, a criança não concebe mais os direitos iguais dos indivíduos, mas considera as situações particulares existentes no seu julgamento.

Finalmente, Piaget (1994) revela que:

a autoridade adulta, se bem que constituindo, talvez, um momento necessário na evolução moral da criança, não basta para constituir o senso de justiça. Este só se desenvolve na proporção dos progressos da cooperação e do respeito mútuo, de início, cooperação entre crianças, depois cooperação entre crianças e adultos, na medida em que a criança caminha para a adolescência e se considera, pelo menos em seu íntimo, como igual ao adulto (p. 239).

\section{Método}

Neste estudo piloto, optou-se pela abordagem qualitativa, já que o objetivo foi investigar o julgamento moral nas crianças, não somente o que é justo e injusto, mas também o porque desse posicionamento nas histórias apresentadas aos participantes. Segun- 
do Haguette (1999), “os métodos qualitativos enfatizam as especificidades de um fenômeno em termos de suas origens e de sua razão de ser" (p. 63).

Cruz Neto (1994) salienta a entrevista como o procedimento mais usual de coleta de informações, entre as diversas técnicas existentes na pesquisa qualitativa, em que se realiza uma conversa com propósitos bem definidos e que pode ser de natureza individual ou coletiva. Nesse sentido, Triviños (1994) relata que a entrevista semi-estruturada é um dos principais meios de coleta de dados, pois a inserção de perguntas a partir do relato do participante traz o enriquecimento da investigação. Assim, nesse estudo foi realizada a entrevista semi-estruturada coletiva como procedimento de coleta de informações e, posteriormente, os dados obtidos foram analisados.

Porém, é preciso considerar algumas questões referentes a entrevista como meio de coleta de informações. A primeira delas trata da presença do entrevistador, no caso o único adulto, que pode levar ao intimidamento da criança ou à emissão de respostas para agradar quem pergunta. A segunda questão relaciona-se ao fato de que a situação de entrevista pode levar à perda da espontaneidade e a certa ansiedade. Mais especificamente, ressalvas devem ser feitas quando são narradas histórias e solicita-se o seu julgamento moral, pois podem suscitar uma "lição de moral" por parte da criança ao adulto. Quanto às técnicas de coleta de dados, utilizadas por Piaget, Biaggio (1972) diz que "são bastante subjetivas, sem falar na ausência de análise estatística" (p. 36). Em contrapartida, Martins (1997) argumenta que a utilização de histórias padronizadas facilmente compreensíveis pelas crianças diminui o risco de resultados equivocados, devido à sua forma de construção e apresentação. Uma crítica ao método clínico utilizado por Piaget, que também é pertinente nesta coleta, se refere à dissociação do pensamento com a ação, visto que são apresentadas histórias não vivenciadas pela criança, o que, provavelmente, pode modificar o seu julgamento moral.
- Descrição dos participantes

Participaram desse estudo piloto quatro crianças na faixa etária de 8 à 13 anos, das quais três eram do sexo feminino e uma do masculino. Quanto à escolaridade, dois participantes (P1 e P2) frequentavam a terceira série, $\mathrm{P} 3$ a quarta série e $\mathrm{P} 4$ a sétima série. Vale salientar que os participantes $\mathrm{P} 1$ e $\mathrm{P} 4$ eram irmãos e P2 e P3 eram irmãs. Os participantes eram provenientes de famílias de classe média, e em ambos os casos, o nível de escolaridade dos pais era de terceiro grau completo.

\section{- Coleta de informações}

Inicialmente a história foi contada e, logo após, verificou-se ela havia sido compreendida. Para tanto, pediu-se às crianças participantes que narrassem a história. Foram contadas cinco histórias padronizadas, extraídas dos estudos de Piaget (1994). A seguir, a entrevista semi-estruturada foi realizada coletivamente, ou seja, com as quatro crianças juntas. As perguntas principais eram referentes à própria história contada, e, à medida que a criança relatava o seu julgamento, outras perguntas foram inseridas no intuito de verificar de que forma e que critérios estava utilizando em suas análises. $\mathrm{O}$ fato de se trabalhar com um grupo de crianças pode interferir nos resultados obtidos, uma vez que a opinião das crianças maiores pode influir nas das menores, mas não foi verificado esse problema devido às características dos participantes.Assim, as crianças menores foram os primeiros a manifestarem o seu julgamento.

\section{- Análise de dados}

Após várias leituras dos relatos transcritos, obtidos na entrevista semi-estruturada, a análise foi realizada, tendo como foco: situação justa ou injusta, tipos de sanção, igualdade ou equidade, e as possíveis influências no julgamento moral. Os resultados foram descritos e alguns relatos recortados, com a finalidade de facilitar a sua compreensão. 


\section{Resultados e Discussão}

\section{- História 1}

"Um menino brincava em seu quarto, enquanto seu pai trabalhava na cidade. Depois de algum tempo, teve vontade de desenhar. Mas não tinha papel. Lembrou-se então que na escrivaninha de seu pai havia belas folhas brancas numa gaveta. Foi sorrateiramente procurá-las, encontrou-as e tirou todas. Quando o pai voltou, verificou que a gaveta estava em desordem e acabou por descobrir que haviam roubado o papel. Foi logo em seguida, ao quarto do menino e viu no chão todas as folhas rabiscadas com lápis de cor. Então, muito zangado, deu uma boa surra no menino".

"Eu vou lhe contar agora uma outra história, que é quase a mesma, mas não totalmente, pois, aqui, acaba de outra maneira. O pai não o puniu. Explicou-lhe apenas que não estava certo. Disse-lhe: Quando você não está, quando vai à escola, se eu lhe roubasse brinquedos de seu armário, você não gostaria. Então, quando eu não estiver, você não deve nunca mais roubar o meu papel. Isto não me agrada. Não é bonito fazer isso".

"Agora, estes dois meninos, depois de alguns dias, brincavam cada um em seu jardim. Aquele que fora punido estava em seu próprio jardim e aquele que não fora punido brincava também em seu próprio jardim. Então, cada um encontrou um lápis de cor. Era o lápis de cor do pai deles. Lembraram-se imediatamente de que o pai dissera, ao meio dia, que perdera o lápis de cor na rua e estava aborrecido, porque não poderia mais achá-lo. Pensaram então que, se escondessem o lápis de cor, ninguém saberia de nada e não haveria punição".

"Muito bem! Um dos dois guardou para si o lápis de cor e o outro o levou ao pai. Adivinhe qual foi que o devolveu: será que foi aquele que fora bem punido devido ao papel ou aquele ao qual apenas foi explicado?".
Todos os participantes opinaram que a criança que devolveu o lápis foi aquela cujo pai explicou o porquê de não se pegar objetos pertencentes a outros sem o consentimento. Ainda, os participantes responderam a essa questão de forma enfática:

"Que o pai falou!" (P1)

"O que explicou!" (P2)

Foi possível perceber, nos relatos dos participantes, a preferência pela sanção por reciprocidade, do tipo simples repreensão, sem nenhuma punição física à criança infratora. Quando justificaram o seu julgamento, segundo os relatos dos participantes, a punição física (sanção expiatória) não teria o efeito de prevenir a reincidência de uma conduta inadequada:

"Por que o pai explicou, e o outro só bateu, não falou nada, né? Como que o moleque vai entender, né?" (P2)

“É porque ele não aprende." (P2)

"Acho que o menino que pegou o lápis, assim de volta, é o que o pai bateu, e o que devolveu é o que o pai explicou." (P4)

“... acho que o menino nem entendeu." (P3)

Em relação a sanção expiatória, verificou-se que, para os participantes, a punição física levaria a ocorrência de sentimentos indesejados e negativos:

"Porque ele deve ter ficado com raiva." (P1)

Mais especificamente, o participante $\mathrm{P} 4$ salientou, em seu relato, os sentimentos provocados na criança consequente a sua conduta inadequada, após a orientação do pai. Tal sentimento refere-se a ruptura do elo de solidariedade. Piaget (1994) diz que a compreensão de uma conduta inadequada por medidas apropriadas indica à criança a ruptura do elo de solidariedade.

"Eu acho que o menino que levou a explicação, assim do pai, deve ter sentido alguma coisa, aí lembrou da explicação, aí devolveu.” (P4)

"Agora o que apanhou, ele deve ter visto uma imagem ruim, assim do pai, alguma coisa assim, então ele pegou o lápis para ele.” (P4) 
Conforme os relatos, verificou-se que os participantes optaram por medidas de reciprocidade, e que a explicação sem punição física levaria à menor possibilidade de reincidência. Segundo Piaget (1994), a tendência pela sanção por reciprocidade corresponde à moral da autonomia e da cooperação.

\section{- História 2}

"Uma mãe tinha duas filhas, uma obediente, outra desobediente. Gostava mais daquela que obedecia e dava-lhe os maiores pedaços de doce. O que você acha disso?"

Quando os participantes foram questionados se a conduta da mãe era correta, dar mais doce a filha obediente, as respostas foram as seguintes:

"Não!” (P2)

"Nem eu!" (P1)

"Nem eu!" (P3)

Portanto, todos reprovaram a conduta da mãe em relação as suas filhas, mesmo os participantes P1 (8 anos) e P2 (9 anos). Já Rambert, citado por Piaget (1994), obteve como resultado em sua pesquisa, com a mesma história: $70 \%$ das crianças de 6 à 9 anos e apenas $40 \%$ das crianças de 10 aos 13 anos aprovaram a mãe.

Em relação a justiça distributiva, prevaleceram as tendências igualitárias:

"Tinha que ser o mesmo, repartido. Igual!" (P3)

"Por que as duas são iguais, são filhas da mesma mãe." (P2)

“... a gente ganha a mesma coisa da mãe." (P1)

Somente o participante P4 demonstrou, em relação à justiça distributiva, tendência à equidade:

"... se a mãe achar que a outra é mais obediente e merece mais." (P4)
Vale salientar que o participante $\mathrm{P} 4$ considerou a conduta da criança, ser desobediente, como consequente ao tratamento desigual da mãe em relação às filhas:

"Eu acho que talvez a que não obedecia, era desobediente por que talvez ficava com ciúmes por que a outra ganhava mais pedaço, alguma coisa assim." (P4)

Já o participante P1 utilizou-se de suas experiências anteriores, e a sua própria condição, no seu julgamento:

"É assim, tem vez que eu sou desobediente, tem vez que eu não sou, então ... nem por isso ... tinha que ser diferente." (P1)

Piaget (1994) salientou que o fato de se considerar a situação interiormente, influenciado pelas experiências vivenciadas ou apenas observadas, mostra que as crianças não simularam uma lição de moral ou um verbalismo, mas partiram da cooperação, fonte de compreensão mútua, em seus julgamentos.

\section{- História 3}

"Era uma vez uma mãe que passeava com os filhos às margens do Ródano, numa tarde de feriado. Às quatro horas, deu um pãozinho a cada um. Cada um pôs-se a comer, com exceção do menor, que estava distraído e deixara cair o pão na água. Que fez a mãe? Devia dar-lhe outro?"

Piaget (1994) descreveu três tipos de respostas que podem ser emitidas: não dar outro pão (sanção); dar um outro pão, para que cada um tenha o seu (igualdade); ou dar outro pão por se tratar de uma criança pequena (equidade). Nenhum dos participantes foi favorável à sanção. Ao contrário, prevaleceu a igualdade:

"Eu acho que tinha que dividir." (P3)

"Não, pega de todos e começa a dividir, o que sobrar ... dividir igualzinho.”(P2)

“... todas as crianças dividiam ..." (P4) 
O fato de a criança ter ficado sem o seu pão e ser a menor do grupo levou os participantes a um julgamento moral diferenciado, provavelmente provocados pela compaixão, notando-se então, uma tendência à equidade:

“... ela tinha que dar para ele ou dar o dela para ele, ele é pequenininho.” (P2)

"Os maiores podiam dar por que, às vezes, os pequenos precisam de mais alimento que os maiores." (P4)

Porém, os participantes modificaram a sua resposta, dar outro pão à criança, caso a perda do pão não tenha sido consequente ao desajeitamento da criança, mas devido a uma conduta inadequada. Portanto, nessa questão os participantes consideraram a intencionalidade ou não do ato, e de acordo com esse dado, deveria ou não receber outro pão:

“... se jogasse de propósito não!” (P3)

“... se jogasse, a mãe não tinha direito de dar para ele ..." (P2)

“... por que ele é sapequinha, né? E joga assim, aí a mãe não vai poder dar para ele, agora se ele derrubou sem querer, aí divide.” (P2)

As intenções do ator são consideradas em seus julgamentos, segundo Martins (1986), somente por crianças maiores (em torno de 11 anos). $\mathrm{O}$ mesmo autor ainda argumenta que as crianças menores (em torno de 7 anos) julgam os atores em função das consequiências de suas ações. Observou-se que os participantes $\mathrm{P} 2$ e P3, mesmo com menos de 11 anos de idade, consideraram a intencionalidade do ato nos seus julgamentos, e também foram solidários à criança, se o seu ato tivesse sido conseqüente ao seu desajeitamento. As crianças reconhecem os estados emocionais e são influenciadas por considerações morais, de modo que, demonstram preocupações empáticas com o sofrimento da vítima ou com a integridade moral do ator que se envolveu numa violação de regra sem intenção (MARTINS, 1997).

\section{- História 4}

"Numa família havia vários irmãos. Todos tinham buracos em seus sapatos. Um dia, o pai mandou-os levar os sapatos ao sapateiro para que os remendasse. Mas, como um dos irmãos, alguns dias antes, desobedecera, o pai disse-lhe: Você não irá ao sapateiro. Pode ficar com seus buracos, pois é desobediente. O que você acha disso?"

Os participantes foram favoráveis à igualdade. Ou seja, todos têm direito ao conserto de seus sapatos, inclusive a criança que desobedeceu o pai:

“O pai não devia fazer isso.”(P2)

“... já que eles são irmãos, aí todos tem direito de ... arrumar o sapato." (P2)

Além disso, os participantes P2 e P3 consideraram não consertar o sapato da criança como uma sanção excessiva:

"Não só por que ele desobedeceu ele não vai ganhar mais. Uma vez só na vida não tem importância, né?" (P2)

"Vai ficar com o sapato furado o resto da vida!" (P3)

Segundo o relato dos participantes, a sanção mais justa seria por reciprocidade, do tipo simples repreensão, inclusive como maneira de se prevenir a reincidência de um ato indesejado:

"O pai tinha só que explicar para o filho ... para ele não fazer mais." (P1)

“... por que se ele não explicar, vai que ele desobedece de novo." (P4)

$\mathrm{O}$ participante $\mathrm{P} 1$ julgou o dilema resgatando as suas experiências anteriores:

"Se fosse o meu pai ele ia explicar, né? Prá não fazer mais isso, mas ele ia consertar."

Mais uma vez, verificou-se a prevalência da igualdade, em crianças a partir dos 8 anos, no julgamento do dilema proposto, confirmando os resultados obtidos por Piaget. Conforme Piaget (1994), uma san- 
ção é injusta quando pune um inocente, a recompensa a um culpado ou não é dosada na proporção exata do mérito ou da falta. Diante disso, os participantes consideraram não consertar o sapato da criança como injusta e excessiva, devido à falta de proporcionalidade entre o ato e a sanção.

\section{- História 5}

"Alguns meninos jogam bola juntos no pátio. Quando a bola sai do jogo e vai rolar na rua, um dos meninos vai, por sua conta, buscá-la várias vezes. Nas vezes seguintes, só pedem a ele que vá buscála. O que você acha disso?"

Os participantes consideraram a situação injusta e ficaram indignados com o fato da mesma criança ser solicitada à buscar a bola:

Que injustiça! (P2)

“... não podia ser só ele, só por que ele vai ajudar, mas sempre vai ele ..." (P1)

A solicitação da mesma criança para buscar a bola foi considerada como injusta, por se tratar de uma situação coletiva. Havia outros meninos brincando, e não foi correto o sacrifício de uma só criança, mas era necessária cooperação de todos para a continuidade da brincadeira. A situação coletiva do jogo, provavelmente, reforçou os participantes a optarem pela igualdade na história, inclusive com várias propostas de soluções:

“... para ser dividido ...” (P4)

"Tinha que ser assim, cada dia um vai lá pegar, por que todos estão jogando ...... vai dando volta, assim ... (gesticula)" (P2)

"Ou assim, saiu uma vez ia um, sai de novo vai outro ..." (P3)

“... ou todo mundo vai lá ajudar o moleque." (P2)

"Cada vez que a bola saísse prá fora, cada um tinha que ir buscar ...” (P4)
Dell'Aglio E Hutz (2001) apontaram, em seus estudos, três estágios evolutivos de justiça nas crianças: autoridade, igualdade e equidade, formulação que coincide com as idéias de Piaget. Segundo os autores, as crianças de 5 a 6 anos utilizaram predominante regras de autoridade, as de 9 e 10 anos, as regras de igualdade; os adolescentes, as regras de eqüidade. Assim, os participantes, nesse estudo, utilizaram as regras de igualdade em seus julgamentos. A cooperação predominou no julgamento dos participantes, denotando-se um forte sentimento de solidariedade. Nesse sentido, Martins (1986) relata que o respeito mútuo é necessário e pertinente à fase de autonomia ou de cooperação.

\section{Considerações Finais}

De acordo com o desenvolvimento sócio-moral descrito por Piaget, os resultados obtidos na entrevista, por meio de histórias padronizadas, evidenciaram que os participantes estão na fase de autonomia ou de cooperação, com tendência predominante à igualdade em seus julgamentos. Pode-se concluir que a seqüência de estágios do desenvolvimento moral na criança, descrita por Piaget (1994), foram encontrados neste estudo. A investigação realizada não possibilita uma ampla visão do desenvolvimento sócio-moral de crianças, por se tratar de um estudo com número restrito de participantes, mas demonstra a atualidade da teoria proposta por Piaget acerca do julgamento moral e a possibilidade de obter resultados significativos mediante a utilização de histórias padronizadas. Finalmente, outras investigações devem ser realizadas acerca do tema, já que as diferenças culturais podem influir significativamente nos resultados. 


\section{Referências}

BIAGGIO, A. M. B. Desenvolvimento moral - análise psicológica. Arquivos Brasileiros de Psicologia Aplicada, Rio de Janeiro,v. 24, n. 1, p. 7-40, 1972.

DELL'AGLIO, D. D.; HUTZ, C. S. Padrões evolutivos na utilização dos princípios de justiça distributiva em crianças e adolescentes no sul do Brasil. Psicologia: Reflexão e Crítica, Porto Alegre, v. 14, n. 1, p. 97-106, 2001.

HAGUETTE, T. M. F. Metodologias qualitativas na sociologia. Petrópolis: Vozes, 1999. 224p.

MARTINS, R. A. Intenção e consequência no julgamento moral. Rio de Janeiro, 1986. 76 f. Dissertação (Mestrado) - Instituto Superior de Estudos e Pesquisas Psicossociais da Fundação Getúlio Vargas), Rio de Janeiro.

Concepção de roubo em pré-escolares. Educação \& Sociedade, São Paulo, ano 18, n. 59, p. 351-66, 1997.
CRUZ NETO, O. O trabalho de campo como descoberta e criação. In: MINAYO, M. C. S. (Org.):

Pesquisa social: teoria, método e criatividade. 7. ed. Petrópolis: Vozes, 1994. p. 51-66.

PIAGET, J. O juízo moral na criança. 2. ed. São Paulo: Summus, 1994.302p.

SALES, E. M. B. O conceito de justiça distributiva relacionado às normas sociais escolares. Psicologia: Reflexão e Crítica, Porto Alegre,v. 13, n. 1, p. 49-58, 2000.

TRIVIÑOS, A. N. S. Introdução à pesquisa em ciências sociais: a pesquisa qualitativa em educação. São Paulo: Atlas, 1994. 175p. 
